\title{
Gender, Creativity and Education in Digital Musics and Sound Art
}

DRAFT OF ARTICLE/ISSUE PUBLISHED IN CONTEMPORARY MUSIC REVIEW (2016)

Georgina Born (*corresponding author)

Faculty of Music

University of Oxford

St Aldates

Oxford OX1 1DB

$\mathrm{UK}$

+44 (0)1865 286079

georgina.born@music.ox.ac.uk

Kyle Devine

Department of Musicology

University of Oslo

PO Box 1017 Blindern

0315 Oslo

Norway

+4722854060

kyle.devine@imv.uio.no

\section{Bios}

Georgina Born is Professor of Music and Anthropology at the University of Oxford. She holds or recently held visiting professorships at McGill University, the University of California, Berkeley, and Oslo University. Her work focuses on cultural production, often in the guise of major western cultural institutions, notably the BBC and IRCAM. From 2010 to 2015 she directed the European Research Council-funded research programme 'Music, Digitization, Mediation:

Towards Interdisciplinary Music Studies'. In 2015 she returned 'officially' for the first time to IRCAM to give a keynote in the 'Tracking the Creative Process in Music' conference.

Kyle Devine is an associate professor in the Department of Musicology at the University of Oslo, and a researcher with the 'Music, Digitization, Mediation' Research Group at the University of Oxford. His books include Decomposed: The Political Ecology of Music (MIT Press, forthcoming), Living Stereo: Histories and Cultures of Multichannel Sound (Bloomsbury 2015) and The Routledge Reader on the Sociology of Music (Routledge 2015). 


\title{
Gender, Creativity and Education in Digital Musics and Sound Art
}

\begin{abstract}
This special issue examines the politics of gender in relation to higher education, creative practices and historical processes in electronic music, computer music and sound art. The starting point is a summary of research findings on the student demographics associated with the burgeoning of music technology undergraduate degrees in Britain since the mid 1990s. The findings show a clear bifurcation: the demographics of students taking British music technology degrees, in comparison to traditional music degrees and the national average, are overwhelmingly male, from less advantaged social backgrounds, and slightly more ethnically diverse. At issue is the emergence of a highly (male) gendered digital music field. The special issue sets these findings into dialogue with papers by practitioners and scholars concerned with gender in relation to educational, creative and historical processes. Questions addressed include: What steps might be taken to redress gender inequalities in education, and in creative, compositional and curatorial practices? How can we combat the tendency to focus exclusively on the 'problem of women' while at the same time ignoring the challenges posed by the marked styles of masculinity evident in these fields? Is the gendering of electronic and digital musics and sound art evident in certain aesthetic directions? And what musical futures are augured by such imbalances?
\end{abstract}

Keywords: music technology; gender; electronic and computer music; sound art; creativity; education; mediation

\section{Introduction}

'Either critical scholars in antiracist, feminist cultural studies of science and technology have not been clear enough about racial formation, gender-in-the-making, the forging of class, and the discursive production of sexuality through the constitutive practices of technoscience production themselves, or the science studies scholars aren't reading or listening — or both.'

- Donna Haraway (1997, p. 35; emphasis in original)

This special issue examines the politics of gender in relation to higher education, creative practices and historical processes in electronic music, computer music and sound art. It stems from two sources. First, it represents an extension of and a response to Georgina Born's and Kyle Devine's (2015) research on music technology, gender and class in contemporary British higher education - a study that is itself an offshoot of Born's larger research programme, 'Music, Digitization, Mediation: Towards Interdisciplinary Music Studies' (MusDig). ${ }^{1}$ In Born's MusDig

\footnotetext{
${ }^{1}$ For information on the MusDig research programme, see http://musdig.music.ox.ac.uk/. The MusDig programme, directed by Georgina Born, was funded by the European Research Council's Advanced Grants scheme (project number 249598) and located at Oxford University. All URLs in this article were last accessed in March 2016.
} 
ethnographic study of digital art musics ${ }^{2}$ in several British universities and other key sites (e.g. conferences, festivals, performances, funding bodies), it became clear that there was a pronounced gendering both of practitioners and of student populations. These findings about gender took up a theme of Born's (1995) earlier research on computer music, and her current ethnographic observations were quantitatively confirmed when we analyzed a dataset from the Universities and Colleges Admissions Service (UCAS) along with figures from the Higher Education Statistics Agency (HESA). The UCAS demographic data cover five years (20072011) of undergraduate student populations on both traditional music (TM) degrees and music technology (MT) degrees across twelve broadly representative universities. ${ }^{3}$ They show that the TM student population is very roughly balanced in terms of its gender profile (55 percent female to 45 percent male), in accord with the national average for all undergraduate students in the period of the study, while the MT student population is approximately 90 percent male. ${ }^{4}$ The MT degrees instance, moreover, both a lower social class profile and slightly greater ethnic diversity than the TM degrees. These findings have led us to enquire into the historical and social formations that have shaped the present topography, and also to question what these divergent demographics imply for the future of digital musics in the UK. ${ }^{5}$

We presented a summary of this research at the opening of a half-day panel on gender at the New Instruments for Musical Expression (NIME) conference at Goldsmiths' College, University of London in the summer of 2014, which is the second source of this special issue. ${ }^{6}$ We believe this was among the first panels, if not the first, to focus on issues of gender in the important scientific, artistic and professional gatherings manifest in the annual electronic and

\footnotetext{
${ }^{2}$ We use the term 'digital art musics' as a problematic placeholder for a wide space of contemporary genres associated with or departing from earlier electronic, electroacoustic and computer art musics, and sound art.

${ }^{3}$ The sample of twelve institutions includes Bangor University; University of Central Lancashire; De Montfort University; University of East London; University of Edinburgh; Goldsmiths' College, University of London; Huddersfield University; London College of Communication, University of the Arts, London; Manchester University; Queen Mary, University of London; Queen's University Belfast; and York University. In making the selection we consulted a number of senior figures in the field: Michael Clarke, Simon Emmerson, Cathy Lane, Pedro Rebelo, Thomas Schmidt and Simon Waters. We are very grateful for their help and advice, though we should emphasize that they are not responsible for the interpretations and findings presented here. We want to acknowledge the unavoidable reifications manifest in our heuristic metacategories, TM and MT degrees. But the findings that arise from making the broad comparison between them in our view justifies their use.

${ }^{4}$ Our findings rest on figures for student acceptances. It is important to note that while the MT programmes accept more male students in absolute terms, there is a slightly higher acceptance rate for women, which might indicate both an awareness of, and attempts to redress, the gender imbalance.

${ }^{5} \mathrm{We}$ are able to present here only a snapshot of our larger study. For fuller information on our dataset, our figures, our interpretations of the meteoric rise of MT degrees, our analysis of the class dynamics of the two kinds of degrees, and our hypothesis regarding why these bifurcating demographics exist and the historical conditions favouring these developments, see Born and Devine (2015).

${ }^{6}$ The NIME gender panel was a follow-up to two previous events held on this research and its implications: the first, in May 2013 at Oxford University's Faculty of Music, brought together about 30 representatives of the universities and degree programmes in our study; the second, in July 2013 at St Anne's College, Oxford, formed part of a three-day international conference at which we presented the MusDig research to the broad community of scholars and practitioners. Several of the contributors to this issue presented at, or attended, these previous events as well.
} 
computer music conferences - in itself a striking point. ${ }^{7}$ In bringing this analysis to the NIME community, we used the remarkable gender imbalance registered in our research as the platform for a discussion about contemporary creative processes in terms of technological design and use, educational settings, and performance, installation and compositional practices. The panel included position papers by a range of scholars and practitioners and stimulated a wide-ranging discussion. Together with the panelists and audience members, we addressed questions such as: What steps might be taken to redress gender inequalities in education, creative and curatorial practices in these fields? How can we combat the tendency to focus exclusively on the "problem of women' while at the same time ignoring the challenges posed by the marked styles of masculinity evident in these fields? Is the gendering of digital musics and sound art manifest in certain aesthetic directions and/or technological developments? And what kinds of musical and music-technological futures will take shape if the gender imbalance is allowed to persist? Panelists and discussants adopted constructive but critical standpoints, leading to a productive and rich session, while confirming that there are no easy answers - an insight evident in Donna Haraway's robust criticism, quoted at the start of this article, of dominant strands in even putatively 'progressive' science and technology studies (STS) for ignoring the challenges posed by feminist scholarship as well as by questions of race and class. ${ }^{8}$ We are pleased to present here versions of all the NIME position papers, as well as several additional papers that we commissioned to address related topics. Our intention is to place the issues addressed in this Contemporary Music Review high on the agenda of the international fields of electronic and computer music and sound art, since they have languished too long, with the goal of fuelling further debate and progress on these critical issues.

\section{Music, Technology and Gender: Archaeologies of Devices and Genealogies of Discourses}

One of the main questions that arose for us, in light of the strong gendering of the MT degrees, is: how do such educational, social and aesthetic formations take shape? That is, generally, how do social relations get into musical practices, music technologies and their user populations? In the context of NIME, and the field of computer-human interaction (CHI) to which NIME is connected, key insights come from studies of technological design. We invoke perspectives from STS in suggesting that actors are drawn into technological assemblages not only at the stages of testing or use, but through the social imaginaries that inform product conceptualization and design (cf. Oudshoorn 2003). The interest here lies in the kinds of social relations that come to be manifest in technological designs themselves. As Madeleine Akrich (1992) and Steve Woolgar (1991) have argued, the development phase of technology is a key stage in which designers 'script' certain envisaged usages, more or less consciously or intentionally, into their devices, in this way 'configuring' user identities and preferring certain patterns of use.

Assumptions about gender pose a problem in this context, as has been shown by Nelly Oudshoorn, Els Rommes and Marcelle Stienstra (2004) in their empirical research on the creation of new information and communications technologies (ICTs). Through comparative case studies of the design cultures of two online 'virtual' or 'digital cities' developed in the public and private sectors in the Netherlands, Oudshoorn et al. find that the ICT designers in both cases work with a troubling 'I-methodology' (ibid., p. 33). Thus, while these designers aim to

\footnotetext{
${ }^{7}$ We are therefore particularly grateful to Atau Tanaka for inviting us to hold the panel, following his participation in the July 2013 Oxford MusDig conference.

${ }^{8}$ Her targets are such STS scholars as Bruno Latour, Michel Callon, Steve Woolgar and Steven Shapin.
} 
create technologies with all-embracing appeal and usability - to configure the user as 'everybody' - a key slippage is evident in their guiding notion that they themselves, and their own subjective and corporeal experiences of technology, represent this universal user. Since ICT designers are predominantly male, I-methodology hinders their ability to address the potential (and actual) diversity of the eventual population of users, so that the resultant technologies, emerging from gendered conditions and assumptions projected as universal, embody and entrench existing norms - prominent among them gender norms. In their words, 'The dominance of the I-methodology... resulted in a gender script: the user who came to be incorporated into the design of [ICT] matched the preferences and attitudes of male rather than female users. As almost all designers were male and technologically highly competent, they made [ICT] into a masculine technology' (Oudshoorn et al., 2003, p. 44). ${ }^{9}$ To design technologies and interfaces that respond to real social diversity, then, Oudshoorn et al. argue that I-methodology, along with its universalising projections, must be reflexively acknowledged and thereby consciously changed.

Oudshoorn et al. offer a powerful cautionary tale relevant to designers of new instruments for musical expression. And indeed, there is evidence that the NIME community and the field of music technology in general are not exempt from these processes. Pioneering in this regard was Georg Essl's (2003) foundational critique of the first and second NIME conferences with respect to gender - which he developed by probing the problematic assumptions of the emergent field. Essl notes that men outnumber women in NIME-related design and compositional contexts, adding that 'the theoretical work in new music interface technology in recent years is almost exclusively ungendered' (ibid., p. 23). One effect of this 'marked absence of documented gender awareness', he argues, has been to reinforce stereotypical binarisms such as man/woman and nature/technology (ibid., p. 19), thereby resonating with the problems of I-methodology. As an antidote, Essl propitiously uses the work of feminist and poststructuralist critics, notably Haraway and Judith Butler, to stress the potential for NIME to become a space in which gender unawareness and binary presumptions could be pried open-discursively, practically and musically - in order to enable the kinds of posthumanist boundary experiments and humantechnology hybrids envisaged in Haraway's (1991) visionary 'Cyborg Manifesto' to emerge and hold sway. Over a decade ago, Essl therefore powerfully articulated the challenge for NIME to pioneer by mounting a critical institutional transition away from the gender unawareness prevalent across electronic and computer musics - a challenge we intend this special issue to underscore, extend and revitalize. ${ }^{10}$

\footnotetext{
${ }^{9}$ For foundational research on I-methodology, see Akrich (1995). For a comparable perspective from music studies on producers' projections of what audiences will respond to, see Hennion (1989). Both Akrich and Hennion work at the Centre de Sociologie de l'Innovation, the source of actor-network theory. ${ }^{10}$ Essl's (2003) analysis of how certain music-technological works and practices exemplify alternative gendered paradigms remains salutary: he cites in particular Laetitia Sonami's 'Lady's Glove' performances (see also Norman, this issue) and Pikapika by Tomie Hahn and Curtis Bahn. Sonami performed a keynote at NIME 2014 in London. For further significant challenges to gender unawareness in these musical worlds (in addition to those mentioned below, such as Her Noise), see the female:pressure initiative, a network of female composers and artists: http://www.femalepressure.net/fempress.html.
} 
In suggesting that social relations and social imaginaries can be scripted into technological assemblages through design processes, we are not making an essentialist or determinist point; nor are we implying that actual users are constrained to follow the scripts inscribed into the technologies. As Akrich and others have argued, the eventual uses made of any technology cannot be read off the design assumptions; instead, they can and often do entail a break with or a détournement of projected uses. ${ }^{11}$ Thus, in the same way that gender identities are themselves performed, and potentially fluid and varied, as opposed to inherent, and therefore fixed and universal, as feminist criticism has established (e.g. Butler, 1990, 1993), neither are scripts or user-configurations wholly determinant of the actual socialities of interaction or the material assemblages that incorporate technological objects. Rather, we are suggesting that wider social relations, on the one hand, and practices of technological design and interaction, on the other, exist in relations of mutual constitution. In other words, they infiltrate and mediate one another, cohering as techno-social assemblages. ${ }^{12}$ Our suggestion here is based on Born's fourfold 'planar' theory of the social mediation of music. In her words:

In the first plane, music produces its own diverse socialities in the guise of the intimate microsocialities of musical performance and practice. ... In the second, music has powers to animate imagined communities ... In the third, music refracts wider social identity formations ... In the fourth, music is entangled in the institutional forms that enable its production, reproduction, and transformation. (Born, 2012a, pp. 266-267)

The technical design process, with its studio-based armory of practical tests, questionnaires and online surveys, can be understood to operate within the first plane of Born's model; that is, design processes entail social interactions equivalent to music's microsocialites. According to Born's model, each of the four planes has a 'certain autonomy', while the relations between them are dynamic and mutually constitutive. ${ }^{13}$ Indeed, what we have identified here is one way in which the third plane - a plane of wider social identity formations manifest in categories of social difference such as gender (but also class, ethnicity, age, religion, nationality) — gets into, and mediates, the first plane-here, the socialities of design practices. These wider social formations do so through problematic techniques such as I-methodology, meaning that the context of design practice - which is all too easy to envision as a small space of interaction that is somehow isolated from wider social and historical forces - is in fact a consequential domain of and site for musical politics, one in which existing cultural categories, as they relate to social

\footnotetext{
${ }^{11}$ The argument is analogous to that made in media and cultural theory about the asymmetry between processes of encoding and decoding, or production and reception, in relation to any text: Hall 1980. ${ }^{12}$ On the concept of an assemblage, see Born (2005; 2012a, pp. 267-268): 'The concept of assemblage... invokes a "multiplicity which is made up of heterogeneous terms and which establishes liaisons, relations between them.... [where] the assemblage's only unity is that of a co-functioning" (Deleuze and Parnet 1987, 69). [It] is characterised by "relations of exteriority" such that component parts may be detached... and plugged into different assemblages in which their interactions will be different. Each component therefore has a "certain autonomy," while the interactions between them are non-linear and mutually catalysing, "only contingently obligatory" (DeLanda 2006, 11, 12)'.

${ }^{13}$ Born (2012a, p. 267): "The first two planes amount to socialities and social imaginaries that are assembled specifically by musical practice and experience. In contrast, the last two planes amount to wider social formations and institutions that condition music, affording certain kinds of musical practice. Such conditions do not amount to an inert 'context': they are folded into musical experience; they both permeate and are permeated by music's intimate socialities and imagined communities."
} 
inequalities, can be inflected, reproduced or even amplified. It follows, as Born highlights, that the temporalities evident in these mediation processes must also be scrutinized: 'in as much as mediation refers to transformational processes, it ineluctably signals questions of temporality: the relative endurance or stability of certain socialities or aggregations, as against the unstable or fleeting quality of others' (Born, 2012a, p. 268). In this light, the gendered mediation of contemporary (music-)technological design shows an astonishing capacity to endure.

In drawing attention to such processes, we aim to encourage all those engaged in musictechnological design and practice - at NIME and beyond - to register this greater social complexity in terms of the ways that wider social relations of gender (but not limited to gender) mediate both the design and the use of new interfaces for musical expression. In other words, the scripting processes that shape the affordances of new music technologies can be said to mediate and materialise various social and historical forces, with political consequences (cf. Born, 2011). In identifying such mediations, we move beyond the I-methodology paradigm in technological design; but we also move beyond those STS analyses of mediation that focus exclusively on the first plane - without recognizing the interferences set up by the other three planes. Here we intend to counterbalance descriptive tendencies in certain schools of STS in which questions of politics may be undeveloped or even ignored. Although this is an established critique (e.g. MacKenzie \& Wajcman, 1985; Winner, 1993; Sterne \& Leach, 2006; Asdal, Brenna \& Moser, 2007), ${ }^{14}$ it is salutary to invoke Peter-Paul Verbeek's work on the politics and ethics of technological design. Verbeek (2006) argues that STS scholarship should enter into a more direct and mutually constitutive dialogue with engineering discourse and design practice, thereby developing a critical and reflexive paradigm in which 'the ethics of engineering design should take more seriously the moral charge of technological products and rethink the moral responsibility of designers accordingly' (ibid., p. 379). ${ }^{15}$ Given the interactions between the first and third planes of mediation in the context of music-technological design, if one of our goals in this journal issue is to forge paradigms of practice and scholarship that are more responsive to social differences and the pluralisms of music as culture - and, more specifically, informed by the politics of gender - then one way to get there is by reflexively reconfiguring the practice of design and its scripting of the ensuing technologies. ${ }^{16}$

Another key perspective suggests that the gendering of the music technology field and of musical interface design refracts wider processes of social differentiation linked specifically to women's relations with technology, and especially the gendering of the science, technology, engineering and mathematics (STEM) disciplines. ${ }^{17}$ Judy Wajcman, a leading feminist STS scholar, offers a summarizing argument:

In contemporary Western society, the hegemonic form of masculinity is still strongly associated with technical prowess and power . . Notwithstanding the recurring rhetoric about women's opportunities in the new knowledge economy, men continue to dominate

\footnotetext{
${ }^{14}$ The opening Haraway quote is indicative of longstanding and continuing feminist criticisms of STS.

${ }^{15}$ For an example of how Verbeek's work might be integrated into sound studies to address the polarized politics of headphones as an audio technology, see Everrett (2014).

${ }^{16}$ One of us (Born) participated in an experimental meeting that attempted to initiate just this kind of reflexive engagement between critical and feminist STS researchers and engineers, a project convened at Microsoft Research New England in March 2014 by Nancy Baym and Jonathan Sterne. For the resulting statement, 'A Manifesto for Music Technologists', see: http://www.musictechifesto.org.

${ }^{17}$ Similar problems of course exist in other fields, too. See for example Ratcliffe and Claire Shaw (2015).
} 
technical work. ... These sexual divisions in the labour market are proving intransigent and mean that women are largely excluded from the processes of technical design that shape the world we live in. (Wajcman, 2010, p. 145) ${ }^{18}$

Wajcman highlights how processes of social exclusion and differentiation are linked not only to the microsocialities of design, but to larger historical and cultural rhythms. Indeed, such processes also manifest at the institutional level (the fourth plane of Born's model). In this regard Lucy Green (1997), Victoria Armstrong (2011) and other researchers in the sociology of music education have shown how girls and women are subject to systematic exclusions particularly in relation to educational programmes in music technology, as borne out also by our research on music technology degrees, in this way institutionalizing the gendering of music technology in both secondary and higher education. Others are now researching how key women composers in the history of electronic music and sound art have been denied equal institutional standing to their male peers, invariably being consigned to the historical margins, while earlier studies show a pronounced gendering of the very institutional division of labour supporting composition in leading computer music centres. ${ }^{19}$

Green, Armstrong and other writers have also shown how gender is manifest in unequal treatment within the microsocialities of classroom settings (the first plane in Born's model). For example, the theory of 'indirect discrimination' suggests that gendered preconceptions inform how teachers interact with and assess their students. This can result not only in subtly divergent assumptions about what counts as musical skill and creativity, but also in more obvious deployments of 'discrete critical vocabulary[ies]' for men's compositions (seen as 'virile' and 'powerful') and women's compositions ('delicate' and 'sensitive') (Legg, 2010, p. 142; cf. Green, 1997, 2012). Additionally, as Armstrong notes (2011, p. 119), technologically oriented classrooms and compositional spaces are often discursively, atmospherically and spatially maledominated, making these areas feel 'off-limits' to female students. ${ }^{20}$ The papers below by Freida Abtan, Simon Emmerson, Cathy Lane, John Richards, Simon Waters and Sally-Jane Norman confront these and related issues, describing several initiatives both inside and outside academia that thoughtfully attempt to open up the worlds of digital music and sound art to more diverse student and practitioner populations.

Musical interfaces and instruments also take on significance as vehicles through which larger musical formations such as genres and their collective modes of affective identification (the second plane in Born's model) become gendered fields of practice. Indeed, notes Green (1997, p. 176), ingrained cultural expectations exist in which both electronic and loud instruments are considered somehow more appropriate for boys than girls. The gendered social imaginaries that take shape surrounding specific instruments and their sonic textures thus contribute to the creation of unequal gender relations in particular music genres. More

\footnotetext{
${ }^{18}$ Numerous other key studies could be cited here, notably those of Wendy Faulkner (2001) and Maureen McNeil (2007).

${ }^{19}$ In addition to the evidence provided by the Her Noise archive (see the paper by Cathy Lane in this issue), Patrick Valiquet is researching the Montreal composer Marcelle Deschennes and Christopher Haworth is researching the composer Maryanne Amacher in this light. Similar political motivations also fuel the present 'rediscovery' of a series of important women electronic composers, including Delia Derbyshire, Daphne Oram and Eliane Radigue. On the institutionalized gendered division of labour in computer music at IRCAM, see Born (1995), particularly chapters 4 and 5.

${ }^{20}$ For analogous exploration of these issues in relation to women music fans, see Stirling, this issue.
} 
specifically, scholarship has shown that men have dominated the technologically-oriented worlds not only of electroacoustic composition and the classical avant-garde, but of rock, hip hop andas Hannah Bosma, Tami Gadir and Christabel Stirling show in this issue - a range of popular and crossover electronic genres, among them dubstep, glitch and DJ-based dance music cultures. ${ }^{21}$

A final perspective stems from cultural-historical analysis of the metaphors and stereotypes that underpin the foundation of what Tara Rodgers (2010b) calls 'audio-technical discourse'. With this concept Rodgers calls attention to the ways in which seemingly straightforward acoustical metaphors - such as conceiving of sounds as 'waves' and 'individuals' - have been mediated by 'the perspective of an archetypal Western, white, and male subject' (ibid., p. v). Her analysis of the gendered epistemology of sound is a kind of historical complement to our arguments about contemporary design practices and Imethodology, on the one hand, and institutional and educational discrimination, on the other. For Rodgers highlights the sedimented historical processes through which human subjects and cultures as well as scientific discourses and technological artifacts become mutually constituted through their convergence on and participation in shared sets of foundational metaphors. Holly Ingleton and Marie Thompson, in their essays here, extend Rodger's approach by examining tone, pitch and timbre (Ingleton) and noise (Thompson). In distinctive ways, both writers argue that these fundamental and apparently neutral acoustic parameters play key roles in the gender politics of digital music and sound art.

In the view of the editors of this special issue, then, it would be unwise to search for a single explanation for, or solution to, the gendering of contemporary digital music and sound art. Rather, we witness a confluence of mutually mediating forces and processes, and they cross all four planes of Born's model. While this means that the exclusionary architecture of such gender politics is sturdy and potentially self-reinforcing, there is also a much more hopeful message: the assemblage-like character of these relations means that real change can begin anywhere, and that critiques and initiatives introduced on one plane have the potential to reverberate across all of the others.

But a further step is necessary here. For while we advocate non-essentialist accounts both of music technologies and of gender relations, we would demur from those performative feminist approaches to the gendering of music-technological assemblages that, by analogy with certain strains of Latourian STS, conceive of this in the terms of gender categories being 'continually constructed, negotiated and renegotiated on an everyday basis [so that] their (so-called) constitutive attributes can be contested' (Ormrod, 1995, p. 36). ${ }^{22}$ Indeed, what is striking about the historical and present-day evidence about the gendering of music technologies as well as the gendering of music composition is that, despite historical change and the continuous exercise of

\footnotetext{
${ }^{21}$ On electroacoustic music and the avant-garde, see Born (1995), Rodgers (2010). On popular music genres see, among many examples, Straw (1997), Bayton (1998), Farrugia (2012), Leonard (2007, 2015). For reflections on the ambivalent gender politics even of a politicized rock avant-garde, see Born (2013). ${ }^{22}$ For such a Latourian performative approach to the gender politics of technology, advocating a 'postessentialist' stance, see Grint and Woolgar (1995). For continuing powerful commentaries on the problems posed by gender to Latour's work and Latourian STS, see Sturman (2006) and Lagesen (2012). A key direction for future work, which we want to register, might be described as a 'post-postessentialist' movement within feminist scholarship. Such work is productively returning to and reconstructing questions of biology (e.g. Pollock 2015, Wilson 2015), which have long been considered anathema to the social constructivist proclivities of feminist theory. At this point, exactly what light this new direction will throw on the relationship between gender and technology remains to be seen.
} 
individual and collective agency and resistance, certain gendered features of both domains tend repeatedly to recur, to stabilize and to endure (cf. Citron, 1993). We therefore urgently need to develop and adopt theories, beyond concepts of performativity, ${ }^{23}$ that can account both for flux and resistance, and for endurance - and a gender politics of technology that builds on these realities.

\section{About the Papers}

The papers in this special issue fall into three main groups: critical - and sometimes personal, auto-critical-reflections on gender politics in relation to creative, educational, professional and other institutionalized practices in both academic and non-academic settings (Abtan, Emmerson, Lane, Norman, Richards, Waters); historical excavations of the gendered ideologies that subtend contemporary creative practices and discourses (Ingleton, Thompson); and analyses of the gendered mediation of aesthetic qualities, creative practices, producer identities and audience formations in genres including dub reggae, techno, glitch, dubstep and grime (Bosma, Gadir, Stirling).

The first group of papers brings questions of creative practice into dialogue with the contributors' experiences in diverse institutional, educational, professional and non-academic settings. Indeed, a key issue in several of the papers is that of the boundary between academic and non-academic contexts and cultures: how the two broad domains differ, and what each affords, regarding the gendering of music-technological practices. As a starting point, Richards outlines how he came to establish Dirty Electronics, a novel form of creative practice that he has cultivated mainly in non-academic spheres, in which participants with any level of previous experience and skill come together to fabricate and then perform with hand-made electronic instruments. Such a do-it-yourself (DIY) ethos in electronic music, he contends, is part of a wider cultural shift that has seen the rise of related movements including hacking, circuit bending and glitch. As a result of Dirty Electronics's politics of participation (Bishop 2006, 2012), Richards notes a marked leveling of the usual gender imbalance when compared to the gendered norms characteristic of digital musics in formal educational settings. Taken together, he suggests, the DIY movements embody diverse reactions against the presets, prefabricated sounds, universal specifications and capitalist appropriation of musical practice that defined an earlier phase of music's digitization (Théberge, 1997, especially pp. 242-255). Richards therefore sees Dirty Electronics as contributing to a musical-technical politics that aspires to the 'empowerment of the individual in global, corporate societies and [the advocacy of] "democracy" on many different levels'.

Abtan's essay might be read as a counterpoint to Richards. Her argument is that the discriminatory processes identified in the sociology of formal music education literature are equally prevalent in the informal, non-academic, DIY social networks through which circulate the knowledge and skillsets required for successful entry into the creative realms of digital music and sound art. As with more formal centers of learning, she contends, these informal networks have social and cultural dynamics that are invariably gendered male. Abtan bases her analysis both on her experience as an academic teacher and on her active and sustained involvement in a variety of non-academic feminist art and technology initiatives, such as Studio XX in Montréal,

\footnotetext{
${ }^{23}$ For the classic statements on performativity see Butler $(1990,1993)$, and for later critical revisions to this paradigm see Bell (2007) and Schep (2012). For a critique of the limits of the performative turn and related process philosophies in relation to theorizing temporality and historical process, see Born (2012b).
} 
which focus on the promotion of skills- and knowledge-sharing among women (cf. Valiquet, 2014, especially pp. 179ff). Abtan offers an inspirational account of other seemingly simple collaborations, such as a CDR called Ladies Club and the alliance Rock Camp for Girls, which involve hosting workshops, arranging concerts, making music and, crucially, showing others how to do these things. Such initiatives, she proposes, can have major impacts in terms of building a strong community of women in electronic music culture. They work to launch 'women musicians into more visible practices where they [are] able to continue organising the culture they had always wanted to participate in'.

Moving towards the professional and institutional centreground, Emmerson examines reflexively the politics of gender in relation to the history of two of the foremost publicallyfunded British electronic music organisations between 1979 and 2004, in both of which he was centrally involved: the Electro-Acoustic Music Association of Great Britain (EMAS) and, from 1989, its successor, Sonic Arts Network (SAN). EMAS's mandate was to evaluate and enhance composers' access to electronic music facilities in the UK. Yet by examining the minutes of EMAS meetings, Emmerson observes that a key dimension of access went largely unaddressed: gender. Indeed, he registers the total absence of women committee members from 1979 to 1989, noting that despite "sometimes intense and heated discussions on "inclusion and exclusion" in the organization's policies and practices... gender issues were never substantially discussed'. Even after the organization's metamorphosis into SAN in 1989, and the appointment of the first of an increasing number of women board members through the 1990s, as well as the significant contributions made by a few women composers, a gender-balanced committee membership never materialized. Emmerson offers no easy answers for this scenario, recognizing the centrality of 'technology' in the compositional realms serviced by EMAS and SAN and citing research suggesting that a focus on technology, as a stereotypically masculine domain, may present a problematic barrier for women entering the field. He concludes with guarded optimism, suggesting that the gradual expansion of eletroacoustic music 'into a much wider diversity of sonic arts practice' - a diversity that, crucially, for Emmerson, is less centred on technology as such — has contributed to 'a redefinition of the field ... subverting any combative need [for women] to "break into" the original, much narrower area' (his emphases).

In marked contrast, Lane discusses a series of recent feminist initiatives in the university context in which she has taken on leadership roles. These projects aim to build, and positively institutionalize, knowledge about women's contributions as musicians, composers, artists and feminist activists, in this way counteracting the institutionalized absence of women from the prevailing histories of music and sound. Among them are the Her Noise Archive and the postgraduate initiative Sound::Gender::Feminism::Activism, both of which revolve around questions of gender in sound-based arts, while also cultivating international networks of researchers and practitioners working in these areas. The mission of the Archive, she writes, in addition to its curatorial function, is to 'create new work, contexts, exhibitions, and formats for sharing and developing this research ... as well as developing [feminist] perspectives that can challenge and enrich the common assumptions and orthodoxies of sound arts practice, history, theory and curation'. Crucially, Lane notes, despite significant efforts 'designed to widen participation ... both inside and outside formal education', a gender imbalance persists in the contemporary field of sound art. Her conviction is that the work of Her Noise, coupled with curriculum developments that include mandatory training in feminist theory, gender theory and queer theory, will help to instigate a 'seismic cultural shift in the critical and contextual frameworks that surround sound art, contemporary music and music technology'. Lane’s 
interventions may be based in the academy - at the London College of Communication, University of the Arts, London-but they broker creative connections to a number of counterhegemonic practices beyond academia.

Of course, the gender issues facing the digital music and sound art communities are not exclusively those of women's access or participation, or those to do with stereotypes of femininity. As Waters argues in his contribution, there are also myriad problems facing these fields with regard to the reproduction or intensification of certain entrenched styles of masculinity. In response to this situation, he develops a strongly anti-essentialist set of reflections on the constructedness and potential fluidity of gender divisions and gendered subject positions across music education, the history and current state of music instrument technologies, workplaces and compositional spaces. Reflecting on his experiences at the Sonic Arts Research Centre (SARC) at Queen's University Belfast, Waters argues that the various pairings of gender and technology in such contexts often function in the service of 'a self-perpetuating narrative of disempowerment rather than stimulating a recognition of and a positive concern with difference and diversity'. He thus advocates the creation of alternative, 'less gendered' narratives that depict 'technology as relational and connective'. In this light, he ends on a note of determined positivity: 'As a 21st-century human, I wish to explore the extents and limits of my selfhoods.... [I]n musicking I can, to an extent, put my "self” into abeyance. Musicking can afford an inquisitiveness with respect to otherness... and perhaps... engender plural socialities'.

The papers by Ingleton and Thompson take, in part, historical perspectives, furnishing critiques of the gendered epistemologies of sound that underlie many of the discourses on digital music and sound art. Ingleton builds explicitly on Rodgers' earlier work, developing a critique of audio-technical discourses in relation to concepts of tone, pitch and timbre. She suggests that these properties of sound have long been construed through problematic metaphors of purity and natural order, associated not only with the binary categories of gender but also sexuality and race. By drawing on a range of feminist, queer and postcolonial theories, Ingleton argues that pitch continuity and tonal purity reflect historical norms in which heterosexuality and whiteness were understood as expressions of a so-called natural order. 'In this way', she contends, 'the norms of bodily transcendence, purity and coherence embedded in dominant definitions of pitch ... can be seen as paralleled by, or transposed from, norms of social organization materialized in hegemonic representations of "white masculinity" and "white femininity". Ingleton then weaves this perspective into an analysis of an installation by Kim Gordon and Jutta Koether which, she argues, challenges the ideologies identified in the earlier part of the essay by performing a 'blasphemous detuning' of pitch and timbre as sonic parameters.

Thompson develops a broadly parallel critique of the normalized associations between sound and gender, but she focuses on a different keyword in audio-technical discourse: noise. She begins by showing how numerous negative female stereotypes - 'shrieking and hysterical madwomen, deadly sirens, meddling gossips and hectoring scolds, to the "toxic" twitter feminists' - have throughout history been articulated to a particular politics of sound. Whereas 'bad women' succumb to an ostensibly 'natural' noisiness, 'good women' are understood to know how to control their auditory presence. In contrast to this normative paradigm, in which 'noise' is made legible against the backdrop of a patriarchal audio-technical discourse, Thompson re-inscribes the term with a positive, productive political potential. She finds backing for such a project in a reading of Shannon's and Weaver's classic model of communication, suggesting that noise has the capacity to blur boundaries between otherwise apparently stable categories, and that this quality allows it to work against the essentialisms and binarisms that 
undergird apparently 'natural' associations between noise and negative stereotypes. Indeed, Thompson charts recent endeavours in which noise figures prominently as a way of combatting the 'invisibility and inaudibiltity of female musicians, sound artists and producers' in historical and contemporary sound art and other musics (e.g. the Her Noise project, Rodgers' Pink Noises, and musical compilations such as Women Take Back the Noise and Ladyz in Noyz). Despite there being no unifying politics of noise in such initiatives, Thompson argues that 'noise has some promise from a feminist perspective: [these initiatives] point to a shift from feminized noise to feminist noise'. Thompson thus envisages future creative and scholarly work that would seek to operationalize 'the generative, transformative' potential of feminized noise.

The following three papers all address, in distinctive ways, the interrelations between aesthetic qualities, creative practices and producer identities in electronic and digital popular musics. Bosma's contribution centres on glitch music. She notes that glitch could represent a source of optimism or subversion in the popular music sphere, insofar as the genre's valorization of an 'aesthetics of failure' might seem to open up alternative perspectives in which audio technologies 'are staged as resistant materialities, as multifunctional media technologies with musical and socio-political impacts'. Nevertheless, and notwithstanding the significant contributions to glitch made by certain women artists, Bosma contends that the genre remains, demographically and symbolically, a male-gendered field of creative practice which, furthermore, is anchored in longstanding and problematically gendered audio-technical discourses. As she puts it, 'Losing control in glitch music is actually at the service of regaining control-like a phase in the development of the classic masculine hero'. The answer to Bosma's driving question - 'Is glitch music allied with a non-masculine aesthetics and praxis?' - is therefore, for the most part, 'no'. Yet she remains open to the possibility that 'alternative conceptions of glitch... may revitalize the [genre] and sensitize it to gender'.

Gadir provides an ethnographically-grounded critique of the gendering of a different but related world of technologically-mediated creative musical practice: DJ-oriented dance music cultures, especially techno. Where certain scholars have highlighted the progressive, inclusive and/or post-feminist politics of electronic dance music cultures, Gadir draws attention to a range of 'everyday' DJ and dance practices in which women are subject to sustained prejudice and harassment. They include: pressures for women DJs to conform to sexualized and stereotypically 'feminine' presentations of self in promotion and performance; incredulity towards any idea that women can be inventive, or even comfortable, when performing and composing with machines; as well as convictions that certain sonic markers are themselves inherently feminine and capable of drawing women to the dance floor. Gadir thus attests to the continued gendering of this globally ubiquitous musical world, suggesting 'that the theme of gender liberation propagated by much scholarly writing on dance music contrasts starkly with the sexist articulations and behaviours of participants on and off the dance floor, and behind the DJ booth'.

Extending these themes, Stirling's paper combines ethnography with historical and genealogical analysis to argue against the casual essentialisms often evident in popular music criticism and some scholarship in relation to the male-gendering of the Jamaican-British genre 'continuum' (Reynolds 2013) that links dub reggae and subsequent genres like lovers' rock and dancehall to the EDM genres dubstep, drum 'n' bass and grime. Arguing that there is nothing inherently 'masculine' about key sonic markers in these genres such as high volume and heavy bass, Stirling develops a stance akin to Paul Gilroy's 'anti-anti-essentialism' (1993, p. 102), ${ }^{24}$

\footnotetext{
${ }^{24}$ We note tentatively here the resonances and tensions that might be explored between Gilroy's 'antianti-essentialism' and the emergent 'post-post-essentialist' feminist scholarship mentioned in note 22.
} 
fruitfully employing Sara Ahmed's (2004) work to analyze how 'gendered musical attachments and associations can "stick" for long periods of time, becoming ingrained and resilient at an affective and bodily level and, thereby, resistant to change'. On the basis of her multi-site London ethnography of these musical scenes, she shows how gendered assumptions nevertheless mediate and reproduce inequalities in terms of the prevalence of male audiences and the malegendering of performance spaces. The paper is underpinned by Stirling's dialogue with DJ/producer Jack Latham, addressing the politics of gender in relation to his creative practice, and showing how Latham's reflexive engagement with such issues is evident in his desire reciprocally to experiment with, and thereby alter, the aesthetic expectations of the male crowd formations assembled by his music.

Sally-Jane Norman provides an afterword that speaks to how this special issue emerged from the 2014 NIME panel, while forging connections both to our introduction and to the other papers. Continuing Waters' anti-essentialism, Norman-a leading transdisciplinary creative practitioner who has worked inside and outside academia - addresses how gender biases can constrict access to technologically-oriented musics, while resisting oversimplified 'drastic remedies' such as setting gender quotas in various realms of musical participation. Citing Geoffrey Bowker's (2000, p. 15) notion of 'dynamic uncompromise between agonistic groups', itself reminiscent of Chantal Mouffe's (2005) conception of the political - as a space of agonistic struggle, a concept that Mouffe sees as propitious also for artistic activism (2007)—Norman urges the development of 'frameworks that can accommodate... diversity [and that] might allow leveraging of critical and historical stances to give weight to urgent concerns'. She calls for radical curriculum redesign, as in innovative teaching programmes highlighting 'the importance of sensuous knowledge in the realm of sound arts and sound studies', as against the conventional focus on histories of technologies, composers and works. With reference to Florian Schneider's (2010) ideas about educational forms beyond the universities, Norman envisages productive iterative movements between institutions and 'ek-stitutions', which are understood as 'deinstitutionalized and deregulated spaces such as informal networks, free universities, open academies, squatted universities, night schools, or proto-academies'. It is these 'border economies', she argues, that will engender non-binary experiments, reframing our histories, orthodoxies and categories. She summarizes her point, and the point of this special issue, with

potency: 'If we want to account for the resilience of observed gendering and the reproduction of imbalanced musical literacies, we need to recognize these differences ... avoid tokenism and fleeting celebrations of simplistic value reversals, and above all continue working "on the ground", in ways that treasure diversity and complexity'.

\section{Conclusion}

What becomes clear across the essays in this special issue is that combatting the gendering of contemporary digital music and sound art involves something more than widening participation or balancing demographic profiles. Although these are important goals, by addressing only participation rates and skewed demographics we confront the surface manifestations of wider, more diffuse and resilient long-term processes. The problem, as Patrick Valiquet (2013) puts it, is that such efforts risk amounting to little more than a tokenism that 'takes for granted exactly the kinds of gender binarism and technological essentialism which are the basis for inequality'. This special issue therefore calls attention to the ways in which the gendering of contemporary digital music and sound art is mediated by wider social and historical processes, and thereby 
demands an analysis and a politics that recognize the tenacious gendering of these (and other) music-technological assemblages.

As a complement to efforts at redressing these gender imbalances, including those detailed in some of the papers, the special issue offers a heterogeneous set of perspectives that converge where scholarship meets political motivation and activism, and where the transformative potential of ethnographic research and cultural studies take flight: in critical genealogies of epistemological formations and audio-technical discourses, in the excavation of archaeologies of technological devices, and in the imagination of differently gendered and differently institutionalized aesthetic practices, educational and creative initiatives. It is through such work that contemporary music practices and scholarship might achieve the 'seismic cultural shift' called for explicitly by Lane and implicitly in all the essays.

Indeed, our goal in drawing attention to the variegated and synergistic social relations and histories that mediate the minutiae of design contexts, musical interfaces and creative processes is to recognize, encourage and open up spaces for novel, diverse and as yet unforeseen articulations between subject positions and technological assemblages in digital music and sound art. 'The alternative', Jonathan Sterne notes, 'is a sonic monoculture that will be of relevance to an ever-dwindling set of people and contexts' (2012, p. 28). Indeed, through the very discursive designation of existing music technologies and new musical interfaces as gendered, we and our contributors are 'informationally enriching' (Barry 2005) and politicizing those assemblages, performing one crucial moment in their re-designation, and in this way contributing to their potential transformation. ${ }^{25}$

If we are less optimistic than we might be, and convey that these issues are urgent, it is because the political history of this discursive designation is now at least two decades old. ${ }^{26}$ Following the NIME panel from which this issue has emerged, we therefore urge the communities to which this material relates to organize additional, experimental and imaginative initiatives - in the guise of conference sessions at academic and professional meetings, working groups, alternative educational fora, collaborative workshops, citizens' juries and other meansto advance further the reflexive consideration of the gendering of these musical fields, and how it can most generatively be addressed and altered.

\footnotetext{
${ }^{25}$ On this process of politicizing technologies, see Barry (2013), especially p. 152. See also the exciting and much needed new journal, Catalyst: Feminism, Theory, Technoscience (e.g. Reardon et al. 2015), heralding a wave of new materialist feminist science and technology studies that it is to be hoped will cast new light on the challenges aired in this collection.

${ }^{26}$ See Born (1995). Symptomatically, for some years following the publication of Born's book on IRCAM, online threads in computer music forums debated, often hotly, why the book's critical messages regarding the gendering of computer music were not being picked up and discussed among the computer music community, for example at the annual International Computer Music Conferences.
} 


\section{Acknowledgements}

We would like to thank the original NIME panelists and discussants for making the 'Gender, Education, Creativity in Digital Music and Sound Art' workshop in July 2014 so vital, productive and enjoyable - with additional thanks to Atau Tanaka, Rebecca Fiebrink and SallyJane Norman for their organizational help, and to Alessandro Altavilla for recording the event. We want to acknowledge our considerable debt to Mark Taylor for providing quantitative and other analytical skills that were extremely important in the research that gave the impetus for the NIME workshop. Mark was centrally involved in all three of the events held on this research, and his input and comments throughout were invaluable. David Marquiss also deserves special mention for his early help in gathering and analyzing the data that constitute the basis of this study. Kai Arne Hansen was a valuable conversation partner in the latter stages of drafting our introduction. Thanks, too, to Andrew Barry and Jonathan Sterne for comments and suggestions. 


\section{References}

Ahmed, S. (2004). The Cultural Politics of Emotion. Edinburgh: Edinburgh University Press.

Akrich, M. (1992). The De-Scription of Technical Objects. In W. Bijker \& J. Law (Ed.), Shaping Technology / Building Society: Studies in Sociotechnical Change (pp. 205-224). Cambridge, MA: MIT Press.

Akrich, M. (1995). User Representations: Practices, Methods and Sociology. In A. Rip, T. Misa \& J. Schot (Ed.), Managing Technology in Society: The Approach of Constructive Technology Assessment (pp. 167-184). ed. London: Pinter Publishers.

Armstrong, V. (2011). Technology and the Gendering of Music Education. Farnham: Ashgate.

Asdal, K., B. Brennna \& I. Moser (Ed.). (2007). Technoscience: The Politics of Intervention. Oslo: Unipub.

Barry, A. (2005). Pharmaceutical Matters: The Invention of Informed Materials. Theory, Culture and Society, 22(1), 51-69.

Barry, A. (2013). Material Politics: Disputes Along the Pipeline. Oxford: Wiley-Blackwell.

Bayton, M. (1998). Frock Rock: Women Performing Popular Music. Oxford: Oxford University Press.

Bell, V. (2007). Culture and Performance: The Challenge of Ethics, Politics and Feminist Theory. Oxford: Berg.

Bishop, C. (2006). Participation. London: Whitechapel Art Gallery.

Bishop, C. (2012). Artificial Hells: Participatory Art and the Politics of Spectatorship. London: Verso.

Born, G. (1995). Rationalizing Culture: IRCAM, Boulez, and the Institutionalization of the Musical Avant-Garde. Berkeley: University of California Press.

Born, G. (2011). Music and the Materialization of Identities. Journal of Material Culture, 16(4), $376-388$.

Born, G. (2012a). Music and the Social. In M. Clayton et al. (Ed.), The Cultural Study of Music: A Critical Introduction (pp. 267-268). London: Routledge.

Born, G. (2012b). On Tardean Relations: Temporality and Ethnography. In M. Candea (Ed.), The Social After Gabriel Tarde: Debates and Assessments (pp. pp. 242-244). London: Routledge. 
Born, G. (2013). On Music and Politics: Henry Cow, Avant-Gardism and Its Discontents. In R. Adlington (Ed.), Red Strains: Music and Communism Outside the Communist Bloc. Oxford: Oxford University Press.

Born, G. \& Devine, K. (2015). Music Technology, Gender and Class: Digitization, Educational and Social Change in Britain. Twentieth-Century Music, 12(2), forthcoming.

Butler, J. (1990). Gender Trouble: Feminism and the Subversion of Identity. London: Routledge.

Buter, J. (1993). Bodies That Matter: On the Discursive Limits of 'Sex'. New York: Routledge.

Citron, M. (1993). Gender and the Musical Canon. Cambridge: Cambridge University Press.

Essl, G. (2003). On Gender in New Music Interface Technology. Organised Sound, 8(1), 19-30.

Everrett, T. (2014). Ears Wide Shut: Headphones and Moral Design (unpublished doctoral dissertation). Carleton University, Canada.

Farrugia, R. (2012). Beyond the Dance Floor: Female DJs, Technology and Electronic Dance Music Culture. Chicago: University of Chicago Press.

Faulkner, W. (2001). The Technology Question in Feminism: A View from Feminist Technology Studies. Women's Studies International Forum, 24(1), 79-95.

Gilroy, P. (1993) The Black Atlantic: Modernity and Double Consciousness. London: Verso.

Green, L. (1997). Music, Gender, Education. Cambridge: University of Cambridge Press, 1997.

Green, L. (2012). Music Education, Cultural Capital, and Social Group Identity. In M. Clayton et al. (Ed.), The Cultural Study of Music: A Critical Introduction (pp. 206-216). New York:

Routledge.

Grint, K. \& Woolgar, S. (1995). On Some Failures of Nerve in Constructivist and Feminist Analyses of Technology. Science Technology Human Values, 20(3), 286-310.

Hall, S. (1980). Encoding / Decoding. Chapter 10, pp. 117-127. In S. Hall et al. (Ed.), Culture, Media, Language. London: Unwin Hyman.

Haraway, D. A Cyborg Manifesto: Science, Technology, and Socialist-Feminism in the Late Twentieth Century. In Simians, Cyborgs and Women: The Reinvention of Nature. New York: Routledge, 1991.

Haraway, D. (1997).

Modest_Witness@Second_Millenium.FemaleMan@_Meets_OncoMouseTM. In Modest_Witness@Second_Millenium.FemaleMan@_Meets_OncoMouseTM: Feminism and Technoscience. New York: Routledge. 
Hennion, A. (1989). An Intermediary between Production and Consumption: The Producer of Popular Music. Science, Technology and Human Values, 14(4), 400-424.

Lagesen, V.A. (2012). Reassembling Gender: Actor-Network Theory (ANT) and the Making of the Technology in Gender. Social Studies of Science, 42(3), 442-448.

Legg, L. (2010). 'One Equal Music': An Exploration of Gender Perceptions and the Fair Assessment by Beginning Music Teachers of Musical Compositions. Music Education Research 12(2), 141-149.

Leonard, M. (2007). Gender in the Music Industry: Rock, Discourse and Girl Power. Aldershot: Ashgate, 2007.

Leonard, M. (2015). Gender and Sexuality. In J. Shepherd \& K. Devine (Ed.), The Routledge Reader on the Sociology of Music (pp. 181-189). New York: Routledge, 2015.

MacKenzie, D. \& Wajcman, J. (1985). The Social Shaping of Technology. Open University Press.

McNeil, M. (2007). Feminist Studies of Science and Technology. London: Routledge.

Mouffe, M. (2005). On the Political: Thinking in Action. London: Routledge.

Mouffe, C. (2007). Artistic Activism and Agonistic Spaces. Art and Research, 1(2), http://www.artandresearch.org.uk/v1n2/pdfs/mouffe.pdf

Ormrod, S. (1995). Feminist Sociology and Methodology: Leaky Black Boxes in Gender/Technology Relations. In K. Grint \& R. Gill (Ed.), The Gender-Technology Relation: Contemporary Theory and Research. London: Routledge.

Oudshoorn, N. (2003). Clinical Trials as a Cultural Niche in Which to Configure the Gender Identities of Users: The Case of Male Contraceptive Development. In N. Oudshoorn \& T. Pinch (Ed.), How Users Matter: The Co-Construction of Users and Technology (pp. 209-227). Cambridge, MA: MIT Press.

Oudshoorn, N., Rommes, E. \& Stienstra, M. (2004). Configuring the User as Everybody: Gender and Design Cultures in Information and Communication Technologies. Science, Technology and Human Values, 29(1), 30-64.

Pollock, A. (2015). Heart Feminism. Catalyst: Feminism, Theory, Technoscience, 1(1), 1-30.

Ratcliffe R. \& Shaw, C. (2015). 'Philosophy Is For Posh, White Boys With Trust Funds': Why Are There So few Women? The Guardian (5 January 2015): online. 
Reardon, Jenny, Jacob Metcalf, Martha Kenney, and Karen Barad. (2015). Science and Justice: The Trouble and the Promise. Catalyst: Feminism, Theory, Technoscience, 1(1), 1-48.

Reynolds, S. (2013). The Wire 300: Simon Reynolds on the Hardcore Continuum: Introduction, http://www.thewire.co.uk/in-writing/essays/the-wire-300_simon-reynolds-on-the-hardcorecontinuum_introduction

Rodgers, T. (2010a). Pink Noises: Women on Electronic Music and Sound. Durham: Duke University Press.

Rodgers, T. (2010b). Synthesizing Sound: Metaphor in Audio-Technical Discourse and Synthesis History (unpublished doctoral dissertation). McGill University, Canada.

Schep, D. (2012). The Limits of Performativity: A Critique of Hegemony in Gender Theory. Hypatia, 27(4), 864-880.

Schneider, F. (2010). (Extended) Footnotes on Education. e-flux, 14, 9pp. (online).

Sterne, J. (2012). MP3: The Meaning of a Format. Durham, NC: Duke University Press.

Sterne, J. \& Leach, J. (2006). The Point of Social Construction and the Purpose of Social Critique. Social Epistemology, 19(2-3), 189-198.

Straw, W. (1997). Sizing Up Record Collections: Gender and Connoisseurship in Rock Music Culture. In S. Whitely (Ed.), Sexing the Groove: Popular Music and Gender (pp. 3-16). London: Routledge, 1997.

Sturman, S. (2006). On Black-Boxing Gender: Some Social Questions for Bruno Latour. Social Epistemology, 20(2), 181-184.

Théberge, P. (1997). Any Sound You Can Imagine: Making Music / Consuming Technology. Middletown, CT: Wesleyan University Press.

Valiquet, P. (2013). Unpublished contribution to the Gender Panel at Music, Digitisation, Mediation: Toward Interdisciplinary Music Studies Conference. University of Oxford, UK.

Valiquet, P. (2014). "The Digital Is Everywhere”: Negotiating the Aesthetic of Digital Mediation in Montreal's Electroacoustic and Sound Art Scenes (unpublished doctoral dissertation). University of Oxford, UK.

Verbeek, P.P. (2006). Materializing Morality: Design Ethics and Technological Mediation. Science, Technology and Human Values, 31(3), 361-380.

Wajcman, J. (2009). Feminist Theories of Technology. Cambridge Journal of Economics, 34(1), $143-152$. 
Wilson, E. (2015). Gut Feminism. Durham, NC: Duke University Press.

Woolgar, S. (1991). Configuring the User: The case of Usability Trials. In J. Law (Ed.), A Sociology of Monsters: Essays on Power, Technology and Domination (pp. 58-99). London: Routledge. 